\title{
The Moderating Effect of IT Capability on the Relationship between Implicit Coordination and Team Output Ranking in Coal Mines
}

\author{
Xi Zhang \\ Tianjin University, China \\ jackyzhang@tju.edu.cn \\ Keran Duan \\ Tianjin University, China \\ dkr1993@tju.edu.cn
}

\author{
Zhe Wang \\ Tianjin University, China \\ wangzhe_98@tju.edu.cn \\ Dehu Yin \\ Tianjin University, China \\ 1019209055@tju.edu.cn
}

\begin{abstract}
Mining is a dangerous job which takes place under several hundred meters deep mines and requires multiteam collaboration. Coal miners often encounter critical situations so that traditional coordination methods such as meetings are no longer applicable, and an implicit coordination mechanism needs to be established for front-line mining teams. Many scholars study implicit coordination in emergency management, while this research aims to explore the implicit coordination mechanism in mining teams. Besides, we analyze the impact of a large number of information technology applications (such as intelligent mining robots, intelligent mine system) on implicit coordination. The results verify the significant moderate effect of IT capability on implicit coordination. Finally, we provide some practical suggestions for coal mine managers and coal miners.
\end{abstract}

\section{Introduction}

The fully mechanized coal mining team is a team that produces coal in a coal mine. Coal miners in this team often face critical situations. Sometimes, the underground miners can not fully coordinate and communicate causing coal mine disasters. From 1901 to 2016, there were 278 coal mine accidents (4 or more persons killed in each accident) in India, resulting in 3367 deaths [39]. Some of these accidents caused great losses to the coal mines due to insufficient coordination between ground and underground. At this time, the conventional meeting mechanism is ineffective, so we need to build an implicit coordination mechanism that is conducive to the rapid response of miners. Implicit coordination is another coordination method that is different from explicit coordination. It can be divided into two processes: anticipation and dynamic adjustment [17]. Many previous scholars confirm that implicit coordination can improve team performance [6, $16,21]$, but the mechanism is not clear enough. Besides, the antecedents of implicit coordination are rarely known, especially in the context of coal mines. The lack of the literature leads coal mine managers to know little about how to foster implicit coordination to improve team performance.

In recent years, the information technology is blooming. As a type of energy, coal is vital for every country in the world. The application of information technology in coal mines not only reduces the occurrence of accidents but also increases the output of coal, reducing the waste of coal resources and environmental pollution. So more and more coal mines use new information technologies to proceed energy development all over the world. Such as 1) 5G wireless communication technology [37], 2) ZigBee technology [33], 3) Wireless sensor network [37], 4) Convolutional Neural Networks [34] and so on. A large number of studies analyze the improvement of the individuals and teams productivity by using information technology [1, $12,18,32]$. However, research on the impact of IT on the construction of team implicit coordination is scarce. Therefore, we propose the following question:

In the fully mechanized coal mining team, what are the key antecedents of implicit coordination and what impact does information technology have on implicit coordination?

To address this problem, we extend the research framework of "implicit coordination-team performance". Many scholars previously regard personality traits as the antecedent of implicit coordination $[6,17,25]$, but in the fully mechanized coal mining team, miners come from multiple places across the country, their cognition and habits are different. So we consider the common understanding as the antecedent variable of implicit coordination. 
Then, we consider three moderating variables into the research model. First, as mining is a very dangerous job, with complex working conditions and changeable environments, miners are always required to have the high reaction ability. People who are usually engaged in highly structured jobs may not be suitable for mining. Second, in China, coal mines are usually far away from cities, where transportation is not very convenient and there are few entertainment facilities. When the miners come up from the underground, they usually engage in recreational activities with their workmates. Therefore, we want to study how this will affect the team implicit coordination process if the miners stay in the same physical location all day. Finally, the application of information technology promote communication between underground miners. Therefore, we add three variables of task routineness, virtuality and IT capability into the research framework. Output is an important indicator of the fully mechanized coal mining team, and it is also a direct representation of the team performance in coal mines. Thus, in this study, we use team output ranking to measure the performance of the fully mechanized coal mining team.

The data was collected from Chinese coal mines. We visited 3 coal mines and went down the mine with the coal miners from the fully mechanized coal mining teams. Then we conducted a small interview with them. 5 experts majoring in mining engineering with mining experience and 5 non-mining-related experts were chosen for the preliminary test. Finally, we sent out 200 questionnaires to coal miners. We spent six months to complete the above work.

To the best of our knowledge, we are among the first to apply implicit coordination theory to the scene of fully mechanized coal mining team. Our research provides a new perspective for the application of implicit coordination theory. Our study also contributes to the antecedents of implicit coordination. We introduce common understanding as a new antecedent of implicit coordination. Additionally, this work extends the limited literature on implicit coordination and information technology and clarifies the mechanism of implicit coordination. Our study provides a clear understanding of the relationship between implicit coordination and information technology.

This paper is structured as follows. First, existing studies on implicit coordination are reviewed. Second, we developed a research model and proposed hypotheses. Next, we presented the process of data collection and data analysis. Finally, theoretical and practical implication are discussed.

\section{Literature Review}

\subsection{Implicit coordination theory}

Rico et al. clearly defined the difference between implicit coordination and explicit coordination in 2008 [17]. Implicit coordination means that without direct communication or planning with each other, team members predict tasks and the needs of other team members on their own and then dynamically adjust their behavior accordingly. For instance, when the miners are working underground, it is inconvenient for them to communicate directly. Sometimes their information cannot be delivered in time, and it is impossible for anyone to get all the information. At this moment, miners will take into account other colleagues' professions, interests, experience, and how they have dealt with something in the past, thereby assuming their next actions, and then adjust their behavior to match their colleagues. In this way, miners can complete their tasks together without direct communication.

So, the two basic attributes of implicit coordination are anticipation and dynamic adjustment. Anticipation means that a team member has an anticipation for team tasks in advance without being directly informed of the task requirements or needs of other team members. Dynamic adjustment refers to the continuous actions taken by team members in order to adapt to each other's behavior [17]. Implicit coordination and explicit coordination play different roles in a team. They are not opposites, but complement each other. They can also be converted to each other under certain conditions. For example, in the action phase, more implicit coordination leads to greater team effectiveness. Yet during a transition phase, the opposite is true [16].

\subsection{Implicit coordination and performance}

In recent years, more and more scholars notice some connections between implicit coordination and team performance. Implicit coordination does not require direct verbal communication to make decisions immediately compared with explicit coordination. In the teams, members who coordinate with others implicitly are more likely to perform well in unexpected and stressful environments [13]. Implicit coordination theory has also been applied to various industries. For members of the emergency response team such as SWAT (special weapons and tactics) or police tactical teams, the task environments are complex and dynamic, the great coordination ability is a necessary condition for the team performance [29]. In emergency team of public hospitals, working environment is of critical importance. Team working environment consists of task routineness, task interdependence and virtuality. Mumtaz et al. found that there exists a positive 
correlation between implicit coordination and team performance, while team working environment has a positive moderating effect on the implicit coordination process [11]. The above implicit coordination behaviors all occur within the team, but the implicit coordination behaviors also exist among teams. In an offshore outsourced service project, implicit coordination has a positive impact on project performance among the companies [23]. However, everything has two sides, implicit coordination not only improves team performance, but may hinder team development. For example, during the transition phase of a team, explicit coordination is more helpful for the team to achieve transition, and lays the foundation for higher team efficiency in the action phases, compared to implicit coordination [16].

\subsection{IT applications in Coal Mining Teams}

More and more information technologies are applied to coal mines. In this section, we present the current information technology applications in coal mining teams in Table 1.

Table 1. IT applications in coal mining teams

\begin{tabular}{ll}
\hline \multicolumn{1}{c}{ IT types } & \multicolumn{1}{c}{ IT applications } \\
\hline Exploration & 3D laser scanner; Determine surface coal mines using Convolutional Neural \\
Communication & 5G wireless communication technology [37] \\
Positioning & ZigBee technology for precise positioning of underground personnel [36] \\
Dispatching & Multimedia intellectual dispatching system [38] \\
Mining & Information technology assisted driving system (ADS) [36] \\
Risk Management & Coal Mine Security System (CMSS) [35] \\
\hline
\end{tabular}

Information technology can promote knowledge transfer and generate new explicit knowledge from tacit knowledge, which will enable the coal miners to have a clearer and more straightforward understanding of the thoughts of their colleagues and the requirements of team tasks [31]. Information technology can make the team more coordinated by affecting the knowledge sharing within teams, reducing the dispersion of knowledge, and enhancing the connection between team members, and ultimately improve team performance [30]. Many studies on the impact of IT on team performance are based on the ease of use and usefulness of the technology acceptance model, but rare studies focus on implicit coordination.

\section{Conceptual Model and Hypotheses Development}

This research attempts to find the antecedents of implicit coordination and its impact on team performance in the fully mechanized coal mining team. Hence, we examine the antecedents of implicit coordination from two dimensions, that is, common understanding and personality traits that consists of trust and accountability. These factors exert an influence on team performance by affecting the implicit coordination process of the fully mechanized coal mining team. In this model, task routineness, virtuality and IT capability may have moderating effect. And we will propose our hypotheses in the following content and display these variables in Figure 1.

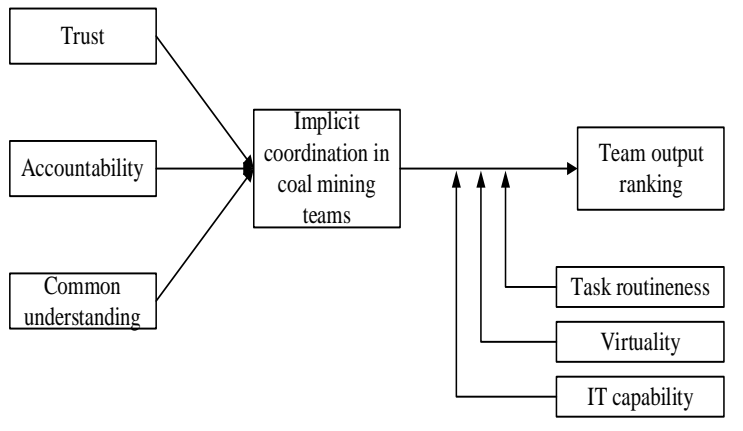

Figure 1. Research model

\subsection{Antecedents of implicit coordination in fully mechanized coal mining team}

3.1.1. Personality traits. Personality traits refers to an enduring state that individuals express through feelings, thinking, and behavior [19]. Some previous studies show that personality traits have an impact on team performance $[15,26]$. Personality traits play an important role in interpersonal relationships in teams [5]. 
In this study, we analyze the impact of trust and accountability on implicit coordination.

Trust is defined as a tendency to believe that others are honest and kind [4]. Trust between team members can promote their cooperation and it can promote communication between team members [22]. It is impossible to achieve that integrating different views of individuals into a consistent view in teams without trust. Hence, in the high-trust teams, individual efforts and contributions are more easily integrated to achieve higher levels of goals and higher levels of coordination. This is good for the team. On the contrary, in the lowtrust teams, it is difficult to integrate the efforts and contributions of individuals due to lack of trust. This makes it difficult to achieve high-level goals because of the low-level coordination of these teams. A high level of trust is related to the active coordination and interaction of the team, which promotes implicit coordination of the team.

Accountability is defined as an implicit or explicit expectation, in other words, the decision or action of a person will be evaluated by some people, and based on these evaluations, the person may be rewarded or punished [9]. In a team, the people perceiving more accountability tend to work harder and show a higher level of work behaviors, which makes the team more coordinated and improves the performance of the team; on the contrary, the people less answerable tend to work not so hard that hinders the development of the team. This suggests that there is a positive and significant relationship between accountability and team performance, because team members are more willing to show favorable work behaviors rather than unfavorable ones [10]. Therefore, in a team, if the team members perceive more accountability, the team will be more coordinated, which can also promote the implicit coordination of the team. Based on the above discussion, we propose the following hypotheses:

Hypothesis 1a: Within the team, trust between team members has a positive impact on the implicit coordination process.

Hypothesis 1b: Within the team, accountability of team members has a positive impact on the implicit coordination process.

3.1.2. Common understanding. Common understanding achieves better team coordination by providing team members with a shared perspective on the tasks. The common understanding is high when team members share the goals of the work and how to complete the task [14]. Common understanding is divided into three dimensions according to the existing literature: common understanding of the task, common understanding of the different parties, common understanding of the organizational goals. Therefore, it takes a lot of effort for a team to reach a consensus. When team members have different views on the overall work process, the skills of other members or personal contributions, the tasks in the team can be frustrating and time-consuming, and eventually it may cause the mission to fail. In general, common understanding is very important for a team, because it can integrate the beliefs of team members to complete the task and make them to reach an agreement, so that the team becomes a more coordinated organic whole. Team members are more likely to predict others' behavior accurately without any communication, when team members have similarity, instead of differences, in cognitive styles [16]. Hence, a high level of common understanding is related to the implicit coordination of the team. So, we assume that:

Hypothesis 1c: Within the team, common understanding between team members has a positive impact on the implicit coordination process.

\subsection{Moderating effect}

In our study, IT capability, task routineness and virtuality are used as moderating variables. The current literature shows that information technology can enhance the transfer of explicit knowledge, meanwhile, it can realize knowledge sharing between different teams. Moreover, information technology can promote the conversion of some tacit knowledge into explicit knowledge and then enhance communication and cooperation between individuals. Once tacit knowledge becomes explicit, this knowledge will become the basis for employees' future learning [31]. Information technology intensity can enhance the potential for knowledge sharing in the team [30].

Cuff et al. give such an example: Alice and Bob are playing a game and they can only communicate implicitly. Due to the use of some information technologies, they got higher scores eventually [32]. As discussed above, information technology can promote knowledge transfer and generate new explicit knowledge from tacit knowledge. In the team that uses implicit coordination as the main communication method, there will inevitably be a lot of tacit knowledge. In this situation, information technology brings a new opportunity: It can convert this tacit knowledge into explicit knowledge, which will enable the coal miners to have a clearer and more straightforward understanding of the thoughts of their colleagues and the requirements of team tasks. In this way, team members are naturally more coordinated, and they will create 
better performance. In a word, implicit coordination has an impact on team performance and information technology enhances this effect.

IT capability is a complex structure that is composed of technical skills, information technology and management resources within the firm [2]. Santhanam \& Hartono [18] found that a firm with a more effective information technology capability will achieve better financial performance, and many studies corroborated this finding [1, 12]. Based on the above discussion, implicit coordination has an impact on team performance. In the fully mechanized coal mining team, the effect of implicit coordination on team performance is greater when team IT capabilities are higher. Thus, we hypothesize:

Hypothesis 2a: IT capability positively moderates the effect of implicit coordination on team output ranking.

Rico et al. defined the concept of task routineness. They believes that highly routine tasks are clearly defined, highly structured, and can be solved by standardized procedures [17]. The impact of implicit coordination on team performance may depend on the levels of routineness of the tasks in a team. Nonroutine tasks have higher requirements for team members. In coal mines, in order to ensure the safety of production operations, coal miners usually make a task plan for the day before going down the mine. Moreover, coal miners will often participate in training to learn the rules and regulations of coal production. When they are in trouble, there are usually some standardized solutions. Therefore, when miners encounter a special situation (different from the regular team situation), relying only on implicit coordination may not be able to solve the problem well, which will eventually lead to a decrease in team performance. Thus, we hypothesize:

Hypothesis 2b: Task routineness negatively moderates the effect of implicit coordination on team output ranking.

Team members communicate with each other by asynchronous technology of low informational value (e.g., email) in the team with high levels of virtuality. While in the team with low levels of virtuality, team members communicate face to face and work in a synchronous manner. In the team with high levels of virtuality, there is less direct and open communication. And due to the impact of implicit coordination, team members will integrate their task information under the conditions of limited communication and interaction, so as to achieve the highest team performance [7,8]. When the levels of virtuality of the team is low, implicit coordination may not be so important to the task of the team [17]. Therefore, we propose the following hypothesis:

Hypothesis 2c: Virtuality positively moderates the effect of implicit coordination on team output ranking.

\subsection{Mediating effect}

Implicit coordination does not require direct verbal communication to make decisions immediately compared with explicit coordination. In the teams, members who coordinate with others implicitly are more likely to perform well in unexpected and stressful environments. In the fully mechanized coal mining team, coal miners accomplish tasks through implicit coordination, and at the same time, the implicit coordination has an impact on the team performance. As demonstrated above, many scholars believe that implicit coordination affects team performance. Therefore, consistent with previous research, we hypothesize:

Hypothesis 3: The implicit coordination process positively affects team output ranking.

\section{Data collection and analysis}

\subsection{Measurement}

In this study, we measure the variables using 7-Point Likert-type scale and the measurements were developed from previous research. Team performance, implicit coordination, trust, accountability, common understanding, task routineness, virtuality and IT capability were measured. The measurements of the implicit coordination (IC) are modified from Curral et al. [13], and the measurements of IT capability (ITC) are based on Song et al. [20]. The measurements of task routineness (TRO) and virtuality (VI) are referenced by Mumtaz et al. [11]. The measurements of trust (TR) are based on Yen et al. [24]. The measurements of accountability (AC) and common understanding (CU) are referenced by Chang et al. [3].

Team performance (TP) is measured based on the output ranking of the fully mechanized coal mining team last quarter. Team performance is very important for coal mines. For coal mine managers, team performance is related to the efficiency of the coal mine. For coal miners, team performance is related to their wages. Shaw et al. use labor hour per ton and accident rates to measure the workforce performance of production workers [33]. For a production worker, labor hour per ton reflects how much work he does to produce a product. It is different from the measurement using scales in previous studies, but is directly derived from objective data. The same is true for the fully mechanized 
coal mining team. Team output can directly measure how much work the coal miners do.

In the fully mechanized coal mining team, team output ranking is not only an important indicator of performance appraisal, but also a direct representation of workforce performance, reflecting how much work the miners do. And we can see which performance of fully mechanized coal mining team better from the team output ranking. Therefore, we use team output ranking to measure team performance of the fully mechanized coal mining team.

To ensure the validity of the measurement, we asked experts with relevant professional knowledge and English translation experience to translate our items into Chinese and then translate them back into English to ensure the consistency of the Chinese version and the English version. We asked 10 users with mining experience to conduct the preliminary test. Then we modified the unclear and ambiguous questions based on the feedback of these users.

\subsection{Data collection}

The data was collected from Chinese coal mines. Firstly, we visited 3 coal mines and went down the mine with the coal miners from the fully mechanized coal mining teams to observe the situation of their teamwork. After going down the mine five times, we got a general understanding of the real working conditions of the miners and IT applications.

Second, we conducted small-scale interviews with them to understand how they feel about their work and teams. Specifically, we named the ten fully mechanized coal mining teams in the order of 1-10 and asked the miners of these teams some questions, such as: "Are you worried about your current work?" "Do you feel scared when you work underground?" "What is the usual atmosphere of your team?" "Do you get along well with other colleagues?"

Then 5 experts majoring in mining engineering with mining experience and 5 non-mining-related experts were chosen for the preliminary test.

Finally, we sent out more questionnaires to coal miners to collect more samples. Specifically, we chose the coal miners from 10 fully mechanized coal mining teams in 3 coal mines and sent them 200 questionnaires. After a total of six months, 102 questionnaires were returned. To ensure the validity of the questionnaires, we removed invalid questionnaires using three criteria, including whether the gender option in the questionnaire was female (in China, almost only males are engaged in underground work in coal mines), whether the questionnaire was submitted within 120 seconds (delete data within 120 seconds), whether the questionnaire had some missing values (delete questionnaires with missing values). We finally retained 91 valid questionnaires through the above procedures.

\subsection{Data analysis}

In this research, partial least squares (PLS) was adopted for data analysis. Specifically, we conducted the Smart PLS 3.3.3. The 91 valid samples we collected from the three coal mines meet the sample requirement for the maximum multiple, so we adopted the structural equation model (SEM) for analysis. We first analyzed the reliability and validity of our research model. Second, we analyzed the path coefficient and significance of the model to judge whether the hypothesis is supported or not.

\section{Results}

\subsection{Measurement model}

We used Smart PLS 3.3.3 to test the measurement model. The results of Quality criteria are presented in Table 2. All the Composite Reliability (CR) and Cronbach's alpha $(\mathrm{C} \alpha)$ are bigger than 0.7 , the average variance extracted (AVE) are over 0.5, which indicates that the data has good convergent validity [27]. Then we measured the discriminant validity using the FornellLarcker Criterion (FLC) and Cross-Loadings. The specific results are shown in Table 3 and 4 . These results indicate that our research has good validity [28].

Table 2. Quality criteria

\begin{tabular}{cccc}
\hline $\begin{array}{c}\text { Measurement } \\
\text { variable }\end{array}$ & AVE & CR & C $\boldsymbol{\alpha}$ \\
\hline IC & 0.700 & 0.874 & 0.782 \\
TR & 0.663 & 0.855 & 0.746 \\
AC & 0.589 & 0.851 & 0.766 \\
CU & 0.639 & 0.838 & 0.719 \\
ITC & 0.612 & 0.863 & 0.789 \\
TRO & 0.807 & 0.893 & 0.765 \\
VI & 0.805 & 0.892 & 0.760 \\
\hline
\end{tabular}

\subsection{Structural model}

In this section, we applied Smart PLS 3.3.3 to analyze the significance of the variables and the path coefficients between them as well as the moderating effect. The bootstrapping was set 5000. The results show that all six hypotheses except $\mathrm{H} 2 \mathrm{~b}$ are supported. The specific results and analysis are shown in Figure 2 and Table 5. 
Table 3. Fornell-Larcker Criterion

\begin{tabular}{|c|c|c|c|c|c|c|c|}
\hline $\begin{array}{c}\text { Measurement } \\
\text { variable }\end{array}$ & ITC & $\mathbf{C U}$ & IC & $\mathbf{A C}$ & TRO & TR & VI \\
\hline ITC & 0.782 & & & & & & \\
\hline $\mathbf{C U}$ & $\overline{0.534}$ & $\underline{0.799}$ & & & & & \\
\hline IC & 0.896 & $\overline{0.542}$ & $\underline{0.837}$ & & & & \\
\hline $\mathbf{A C}$ & 0.658 & 0.586 & $\overline{0.599}$ & 0.768 & & & \\
\hline TRO & 0.658 & 0.540 & 0.580 & $\overline{0.505}$ & 0.899 & & \\
\hline TR & 0.743 & 0.512 & 0.693 & 0.531 & $\overline{0.671}$ & 0.814 & \\
\hline VI & 0.549 & 0.405 & 0.616 & 0.410 & 0.477 & $\overline{0.624}$ & $\underline{0.897}$ \\
\hline
\end{tabular}

$\mathrm{H} 1 \mathrm{a}, \mathrm{H} 1 \mathrm{~b}$ and $\mathrm{H} 1 \mathrm{c}$ propose that the team implicit coordination process is positively affected by trust, accountability and common understanding, respectively. Implicit coordination is significantly related to trust ( path coefficient $=0.413, \mathrm{p}<0.01$ ), accountability (path coefficient $=0.188, \mathrm{p}<0.01$ ) and common understanding (path coefficient $=0.301, \mathrm{p}<0.01$ ), thence $\mathrm{H} 1 \mathrm{a}, \mathrm{H} 1 \mathrm{~b}$ and $\mathrm{H} 1 \mathrm{c}$ are supported. Among them, the coefficient of trust is bigger than accountability and common understanding.

H2a states that IT capability positively moderates the effect of implicit coordination on team output ranking. The hypothesis is supported as the coefficient is positive and significant (path coefficient $=0.288, \mathrm{p}<$ $0.05)$.

$\mathrm{H} 2 \mathrm{~b}$ proposes that Task routineness negatively moderates the effect of implicit coordination on team output ranking. The hypothesis is also supported because of the positive and significant coefficient (path coefficient $=-0.146, \mathrm{p}<0.1$ ).

$\mathrm{H} 3 \mathrm{c}$ states that Virtuality positively moderates the effect of implicit coordination on team output ranking. But $\mathrm{H} 2 \mathrm{c}$ is not supported because the coefficient is not significant (path coefficient $=-0.005, \mathrm{p}>0.1$ ) .

At last, the relationship between implicit coordination and team output ranking is positive and significant (path coefficient $=0.763, \mathrm{p}<0.01$ ), thus $\mathrm{H} 3$ is supported.

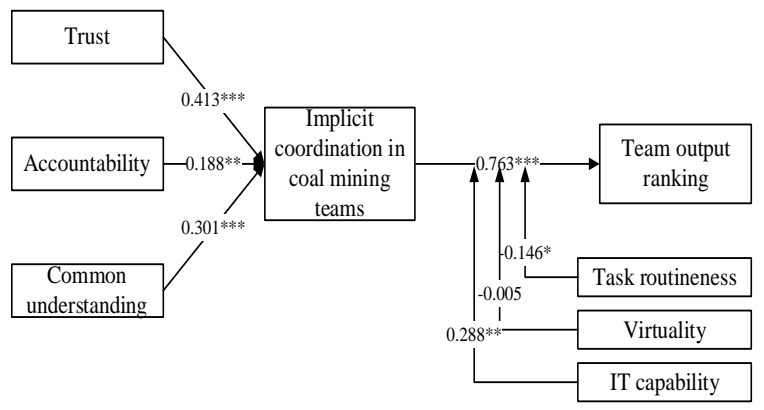

Figure 2. Visualization of the results

\section{Discussion and contributions}

The aim of this study is to find the key antecedents of implicit coordination and examine the effects of information technology on implicit coordination. First, we explain the mechanism of implicit coordination affecting the performance of fully mechanized coal mining team in the study. Specifically, trust, accountability and common understanding have a significantly positive impact on implicit coordination. It is worth noting that the P-value and coefficient of trust are bigger than accountability and common understanding, which indicates that trust has more important impact compared with accountability and common understanding. This also confirms that trust is a very important quality for people. Thence, it is very important for team members to trust each other, because it can promote the team implicit coordination process and ultimately improve team performance. At the same time, accountability and common understanding play a very important role in the process of team implicit coordination. The more team members trust each other, the easier team members to reach a consensus on something, and the more responsible the team members are, in other words, if the interpersonal relationships within the team are more harmonious, it is easier to form better implicit coordination within the team.

Second, in order to analyze the impact of implicit coordination on team performance, we verify the influence of task routineness, virtuality and IT capability. Specifically, task routineness and IT capability has the significant moderating effect on implicit coordination instead of the virtuality. As the hypothesis has stated that task routineness negatively moderates the effect of implicit coordination on team performance while IT capability positively moderates the effect of implicit coordination on team performance. However, the implicit coordination is not moderated by the virtuality. One possible reason is that even though the miners stay together every day, they rarely communicate face-to-face when they work underground. Thus, we believe that the complexity of the situation of fully mechanized coal mining team is the reason why the hypothesis is not significantly supported.

At last but not least, our results demonstrate that implicit coordination has a positive impact on team 
performance, which is consistent with the conclusions of previous scholars.

\subsection{Theoretical implications}

There are many theoretical contributions in this research. First, in recent years, implicit coordination has been extensively studied in various fields, such as companies, government departments, hospitals, schools, and so on. However, few researchers study the application of implicit coordination theory in the context of coal mines. So we explored the impact mechanism of implicit coordination in coal mine scenes, which enriched the research in the field of coal mines and the research field of implicit coordination theory from theoretical perspective.

Second, we use common understanding as an antecedent variable of implicit coordination, which enriches the antecedent research of implicit coordination. And IT capability is added as a moderating variable to the theoretical framework of implicit coordination, which explains the impact mechanism of implicit coordination more clearly. This research not only enriches the literature of implicit coordination research, but also provides a new perspective for future research.

Table 4. Cross-loadings

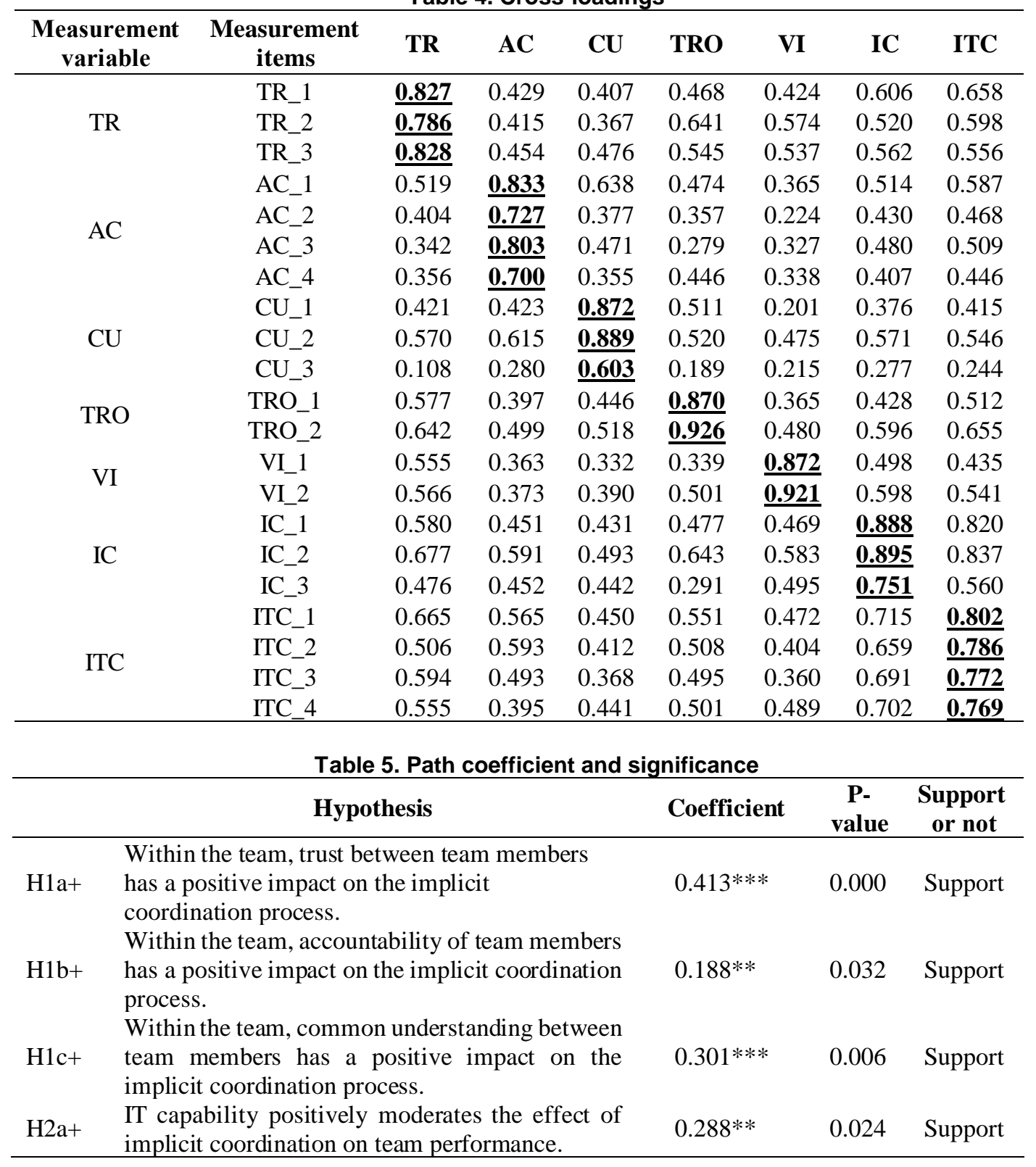




\begin{tabular}{llllc}
\hline H2b- & $\begin{array}{l}\text { Task routineness negatively moderates the effect } \\
\text { of implicit coordination on team performance. }\end{array}$ & $-0.146^{*}$ & 0.094 & Support \\
$\mathrm{H} 2 \mathrm{c}-$ & $\begin{array}{l}\text { Virtuality positively moderates the effect of } \\
\text { implicit coordination on team performance. }\end{array}$ & -0.005 & 0.942 & $\begin{array}{c}\text { Not } \\
\text { Support }\end{array}$ \\
$\mathrm{H} 3+$ & $\begin{array}{l}\text { The implicit coordination process positively } \\
\text { affects team performance. }\end{array}$ & $0.763^{* * *}$ & 0.000 & Support \\
\hline
\end{tabular}

Note: ${ }^{*}=p<.05 ;{ }^{* \star}=p<.01 ;{ }^{* \star \star}=p<.001$

\subsection{Practical implication for coal mine management}

Our research results contribute to some practical implications not only for coal mine managers but also for coal miners. We believe that coal mine managers should improve the team performance from three perspectives. Firstly, from the perspective of information technology, coal mine managers should strengthen and expand the application of information technology in coal mines and introduce more advanced equipment to improve coal mine production performance. Some artificial intelligence and machine learning technologies should also be considered. Subsequently, the research results show that task routineness negatively moderates the effect of implicit coordination on team performance. Thence, coal mine managers should add some nonroutine training and emergency avoidance exercises for coal miners to improve their ability to respond to complex situations. And the work tasks of coal miners should be flexible, rather than constant. At last, from the team perspective, harmonious interpersonal relationship is very important for a team. Therefore, coal mine managers should find ways to ensure the harmony of interpersonal relationships in fully mechanized mining teams and resolve interpersonal disputes in time.

Besides improving the management level of coal mines, there are some practical implications for coal miners. Our research indicates that trust, accountability and common understanding positively affect the implicit coordination process and trust has the strongest impact. Therefore, for the miners of the fully mechanized coal mining team, they should first trust their companions. Meanwhile, they should be responsible for their actions and listen carefully to the opinions of other miners. In addition, miners should understand each other, communicate with each other frankly and openly, and share experience and knowledge about their tasks, so as to reach a consensus.

\section{Limitation}

There are some limitations to our study.

First, our data was collected from 10 fully mechanized coal mining teams in 3 coal mines. The data sources are not diversified and the sample size is relatively small. In the future, we want to collect more samples from more coal mines.

In addition, we used questionnaires to collect samples for this study, which is inevitably subjective, and might result in comprehending deviation. Therefore, we plan to use other data collection and analysis methods such as machine learning and data mining in future research. These objective methods can avoid comprehending deviation.

\section{Acknowledgement}

This work was supported by the National Natural Science Foundation of China [Grant numbers 71722005, 71571133, 71790590, 71790594]; and Natural Science Foundation of Tianjin [grant number 18JCJQJC45900].

\section{References}

[1] J. B. Barney, and D. N. Clark, Resource-Based Theory: Creating and Sustaining Competitive Advantage, Oxford University Press on Demand, 2007.

[2] A. S. Bharadwaj, "A Resource-Based Perspective on Information Technology Capability and Firm Performance," MIS Quarterly, 2000.

[3] H. T. Chang, C. C. Lin, C. H. Chen, and Y. H. Ho, "Explicit and Implicit Team Coordination: Development of a Multidimensional Scale," Social Behavior \& Personality An International Journal, 2017.

[4] J. E. Driskell, G. F. Goodwin, E. Salas, and P. G. O'Shea, "What Makes a Good Team Player? Personality and Team Effectiveness," Group Dynamics Theory Research \& Practice, pp. 249-271, 2006.

[5] Elena, Kurzius, Peter, and Borkenau, "Antecedents and Consequences of Mimicry: A Naturalistic Interaction Approach," European Journal of Personality, pp. 107-124, 2015.

[6] D. M. Fisher, S. T. Bell, E. C. Dierdorff, and J. A. Belohlav, "Facet Personality and Surface-Level Diversity as Team Mental Model Antecedents: Implications for Implicit Coordination," Journal of Applied Psychology, pp. 825-841, 2012.

[7] J. A. Espinosa, J. Lerch, and R. Kraut, " Explicit vs. implicit coordination mechanisms and task dependencies: One size does not fit all," In E. Salas \& S. M. Fiore (Eds.), Team cognition: Understanding the factors that drive process and performance: Washington, DC: APA Books, pp. 177-203, 2004. 
[8] C. Gutwin, and S. Greenberg, "The Importance of Awareness for Team Cognition in Distributed Collaboration," In E. Salas \& S. M. Fiore (Eds.), Team cognition: Understanding the factors that drive process and performance: Washington, DC: APA Books, pp. 107-129, 2004.

[9] A. T. Hall, D. D. Frink, G. R. Ferris, W. A. Hochwarter, C. J. Kacmar, and M. G. Bowen, "Accountability in Human Resources Management," New directions in human resource management, pp. 29-63, 2003.

[10] W. A. Hochwarter, G. R. Ferris, M. B. Gavin, P. Perrewé, A. T. Hall, and D. Frink, "Political Skill as Neutralizer of Felt Accountability--Job Tension Effects on Job Performance Ratings: A Longitudinal Investigation," Organizational Behavior \& Human Decision Processes, pp. 226-239, 2007.

[11] M. M. Khan, S. A. Lodhi, and M. A. M. Makki, "Moderating Role of Team Working Environment between Team Implicit Coordination and Performance," African Journal of Business Management, pp. 2743-2752, 2010.

[12] G. Kim, B. Shin, K. K. Kim, and H. G. Lee, "It Capabilities, Process-Oriented Dynamic Capabilities, and Firm Financial Performance," Journal of the Association for Information Systems, pp. 487-517, 2011.

[13] P. Marques-Quinteiro, L. Curral, A. M. Passos, and K. Lewis, "And Now What Do We Do? The Role of Transactive Memory Systems and Task Coordination in Action Teams," Group Dynamics, pp. 194-206, 2013.

[14] G. A. Okhuysen, and B. A. Bechky, "10 Coordination in Organizations: An Integrative Perspective," Academy of Management annals, pp. 463-502, 2009.

[15] T. A. O'Neill, and N. J. Allen, "Personality and the Prediction of Team Performance," European Journal of Personality, pp. 31-42, 2011.

[16] R. Rico, C. B. Gibson, M. Sánchez-Manzanares, and M. A. Clark, "Building Team Effectiveness through Adaptation: Team Knowledge and Implicit and Explicit Coordination," Organizational Psychology Review, 204138661986997, 2019.

[17] R. Rico, M. Sanchez-Manzanares, F. Gil, and C. Gibson, "Team Implicit Coordination Processes: A Team KnowledgeBased Approach," Academy of Management Review, pp. 163184, 2008.

[18] R. Santhanam, and E. Hartono, "Issues in Linking Information Technology Capability to Firm Performance," MIS quarterly, pp. 125-153, 2003.

[19] M. A. Shaffer, D. A. Harrison, H. Gregersen, J. S. Black, and L. A. Ferzandi, "You Can Take It with You: Individual Differences and Expatriate Effectiveness," Journal of Applied Psychology, 109, 2006.

[20] M. Song, C. Droge, S. Hanvanich, and R. Calantone, "Marketing and Technology Resource Complementarity: An Analysis of Their Interaction Effect in Two Environmental Contexts," Strategic Management Journal, 2005.

[21] A. Stefanini, D. Aloini, and P. Gloor, "Silence Is Golden: The Role of Team Coordination in Health Operations," International Journal of Operations \& Production Management, pp. 1421-1447, 2020.

[22] A. van Hoorn, "Trust Radius Versus Trust Level: Radius of Trust as a Distinct Trust Construct," American Sociological Review, pp. 1256-1259, 2014.

[23] Y. Wang, L. Yi, and C. Canel, "Process Coordination, Project Attributes and Project Performance in Offshore-
Outsourced Service Projects," International Journal of Project Management, 2018.

[24] D. A. Yen, B. R. Barnes, and L. W. Cheng, "The Measurement of Guanxi: Introducing the Grx Scale," Industrial Marketing Management, pp. 97-108, 2011.

[25] M. Yuan, X. Zhang, Z. Chen, D. R. Vogel, and X. Chu, "Antecedents of Coordination Effectiveness of Software Developer Dyads from Interacting Teams: An Empirical Investigation," Ieee Transactions on Engineering Management, pp. 494-507, 2009.

[26] R. Zhang, A. Li, and Y. Gong, "Too Much of a Good Thing: Examining the Curvilinear Relationship between Team --- Evel Proactive Personality and Team Performance," Personnel Psychology, 2020.

[27] J. C. Nunnally, "Psychometric theory," American Educational Research Journal, 1978.

[28] C. Fornell, and D. F. Larcker, "Evaluating Structural Equation Models with Unobservable Variables and Measurement Error," Journal of Marketing Research, pp. 3950,1981

[29] S. Kozlowski, and D. Ilgen, "Enhancing the Performance of Work Groups and Teams," Psychological Science in the Public Interest, pp. 77-124, 2006.

[30] T. Ravichandran, and S. I. Giura, "Knowledge Transfers in Alliances: Exploring the Facilitating Role of Information Technology," Information Systems Research, pp. 726-744, 2019.

[31] V. Sambamurthy, Bharadwaj, Anandhi, Grover, and Varun, "Shaping agility through digital options: reconceptualizing the role of information technology in contemporary firms," MIS Quarterly, 2003.

[32] P. Cuff, and L. Zhao, "Coordination using implicit communication," IEEE Information Theory Workshop, pp. 467-471, 2011.

[33] C. M. Ramya, M. Shanmugaraj, and R. Prabakaran, "Study on ZigBee technology," In 2011 3rd International Conference on Electronics Computer Technology, pp. 297301, 2011.

[34] G. Zhang, Z. Wang, L. Zhao, Y. Qi, , and J Wang, "Coalrock recognition in top coal caving using bimodal deep learning and hilbert-huang transform," Shock and Vibration, 2017.

[35] W. M. Choudhari, "Coal mine security system," International Journal of Applied Information Systems, pp. 812, 2012.

[36] E. Sun, A. Nieto, Z. Li, and V. Kecojevic, "An integrated information technology assisted driving system to improve mine trucks-related safety," Safety science, pp. 1490-1497, 2010 .

[37] L. Ma, "Study on intelligent mine based on the application of $5 \mathrm{~g}$ wireless communication system," IOP Conference Series Earth and Environmental Science, 2020.

[38] Z. Wang, H. Yu, and H. Wang, "Intranet-based multimedia intellectual dispatching system in coal mine," In Computer Applications in the Mineral Industries, pp. 789-792, 2020.

[39] R. M. Bhattacharjee, A. K. Dash, and P. S. Paul, "A root cause failure analysis of coal dust explosion disaster-gaps and lessons learnt," Engineering failure analysis, 2020. 